\title{
Endosinusial Suspension Wash Dosage Form
}

National Cancer Institute

\section{Source}

National Cancer Institute. Endosinusial Suspension Wash Dosage Form. NCI Thesaurus.

Code C149487.

Liquid preparation consisting of a suspension intended for cleaning the sinuses. 